\title{
Grounding Strategies for Solar PV Panels
}

\author{
A. S. Ayub, W. H. Siew \\ Department of Electronic \& Electrical Engineering, \\ University of Strathclyde, \\ Glasgow, Scotland, United Kingdom \\ ahmad.ayub@strath.ac.uk,wh.siew@strath.ac.uk
}

\author{
F. Peer Mohamed \\ Department of System Engineering, \\ Military Technological College, \\ Muscat, Sultanate of Oman \\ pfaisalbe@gmail.com
}

\begin{abstract}
Despite the installation of LPS, the possibility of direct lightning strikes to the solar PV panel frame/structure might still happen. Hence, this paper discusses the grounding strategies for solar PV panels to mitigate hazards from overvoltages when this occurs. In this research project, two strategies are considered for the solar PV assemblies; individual assembly grounding and grouped assemblies grounding. This paper focuses on individual assembly grounding and some preliminary results are presented and discussed.
\end{abstract}

Keywords-grounding, lightning protection system, solar, soil resistivity

\section{INTRODUCTION}

In a solar photovoltaic (PV) farm, solar PV panels are fixed on a grounded structure with bolts and nuts. The structure, the frame of the PV panels, and the bolts and nuts are metallic (together called the assembly) and the layout of all assemblies of the entire solar farm depends on the terrain where they are installed.

Lightning protection systems which are installed on a solar PV farm are mostly based on a Franklin rod (connected to a down-conductor) as the preferred point of attachment. Consequently, it utilises the concept of protective angle or rolling sphere method to determine the protective zone to the solar panel assemblies [1]-[3]. Hence, many such rods would be installed in a solar farm. These lightning rods can be installed either as isolated systems or as non-isolated systems from the solar panel assemblies [3], [4]. Each isolated system consists of a free-standing mast (connected to a Franklin rod at the top) that is erected some distance away from the solar PV assembly Fig. 1a. The non-isolated system is installed as an integral part of the structure of the assembly itself Fig. 1b. For the latter, the structure forms part of the lightning down conductor system [4].

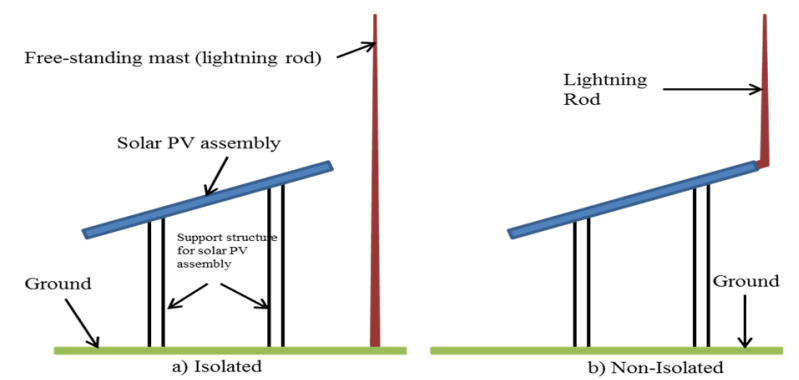

Fig. 1 Isolated \& Non-Isolated Installations: a) Isolated, b) Non-Isolated - 2D drawing
This paper considers the possibility that, despite the installation of the lightning protection system (LPS), direct lightning strikes to the solar PV panel frame/structure might still happen [5], [6]. Hence, lightning current will flow through the PV frame/structure to the ground. Therefore, the project investigates the effects of direct lightning strikes onto a solar PV assembly by considering the overvoltage resulting on the system due to various grounding arrangements.

\section{Methodology}

The assembly considered consists of ten units of $350 \mathrm{~W}$ panels occupying an area of $5 \mathrm{~m} \mathrm{x} 4 \mathrm{~m}$ with a total output of 3.5 $\mathrm{kW}$. Each assembly is inclined for better electrical output but the exact angle of inclination will not be considered in this paper. The dimensions of each solar frame are $1 \mathrm{~m}$ width and $2 \mathrm{~m}$ length and its cross-section is $2 \mathrm{~cm}$ width and $5 \mathrm{~cm}$ height and it is as illustrated in Fig. 2.

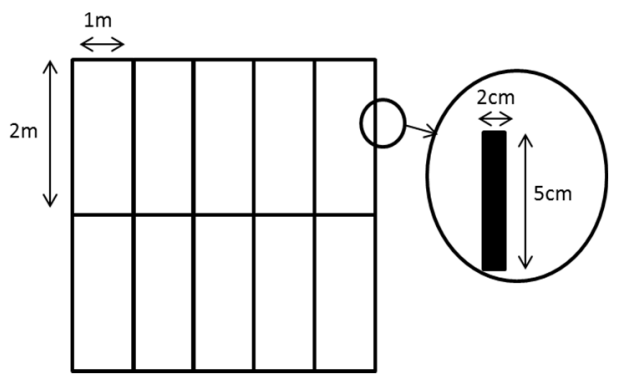

Fig. 2 Illustration of an assembly considered and the blow-up image is the cross section of solar frame

In this investigation, two strategies are considered for the case of protection which is: individual and group groundings. These are illustrated in Fig. 3(a), Fig. 3(b) and Fig. 3(c). For each strategy, an impulse current will be injected at point $\mathrm{A}$ in these figures.

The lightning current considered in this investigation is defined by the double exponential expression as in (1) [2]. The corresponding lightning protection level (LPL) 1 is used in this investigation where the subsequent stroke of $0.25 \mu$ s front time and $100 \mu \mathrm{s}$ tail time current waveform is considered and its parameters are tabulated in Table 1 . In general, subsequent strokes have a higher rate of rise of current in comparison to the first strokes although they have lower peak currents. The resulting voltage drops are then assessed for each strategy with different soil resistivity of $10 \mathrm{ohm}-\mathrm{m}$ and $100 \mathrm{ohm}-\mathrm{m}$ respectively. Furthermore, aluminium is used as the material 
for the solar panel structure and for the down conductor between PV assembly and earth.

$$
i=\frac{I}{k} \times \frac{\left(t / \tau_{1}\right)^{10}}{1+\left(t / \tau_{1}\right)^{10}} \times e^{\left(-t / \tau_{2}\right)}
$$

where $\mathrm{I}$ is the peak current, $\mathrm{k}$ is the correction factor for the peak current, $t$ is the time, $\tau_{1}$ is the front time constant, and $\tau_{2}$ is the tail time constant. Fig. 4 shows the lightning current impulse waveform generated from (1) using parameters tabulated in Table 1 below.

Table 1 Parameters for Lightning Protection Level (LPL) 1 for subsequent stroke $0.25 \mu$ s (front time) $/ 100 \mu$ s (tail time)

\begin{tabular}{|c|c|}
\hline Parameters & Lightning Protection Level (LPL) 1 \\
\hline$I(\mathrm{kA})$ & 50 \\
\hline $\mathrm{k}$ & 0.993 \\
\hline$\tau_{1}(\mu \mathrm{s})$ & 0.454 \\
\hline$\tau_{2}(\mu \mathrm{s})$ & 143 \\
\hline
\end{tabular}

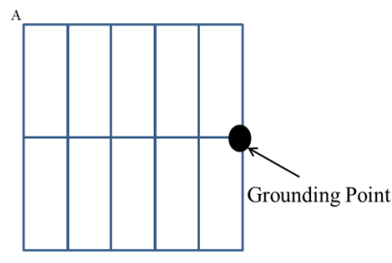

a) Individual Ground, side

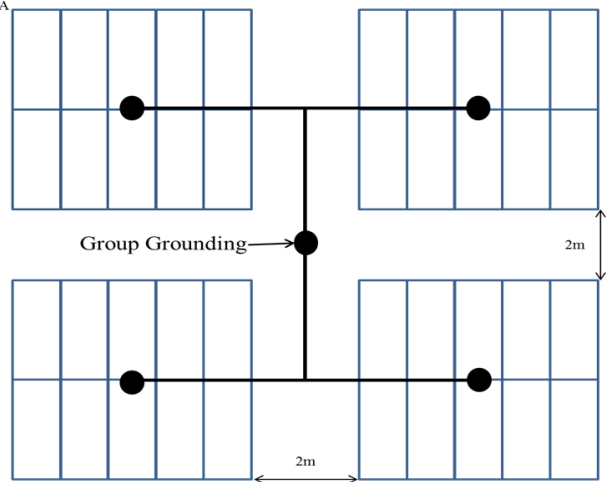

c) Group Ground

Fig. 3 Location of grounding arrangement points; Individual Grounding, a) side - top left, b) middle - top right and c) Group Ground - bottom. All illustrations are based from top view.

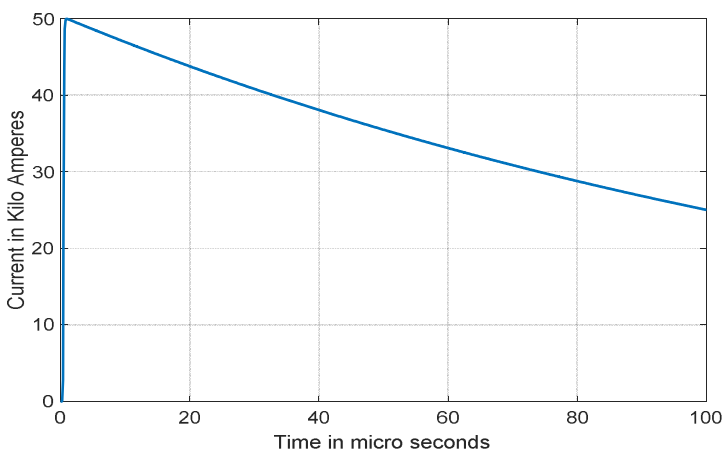

Fig. 4 Lightning current impulse waveform of $0.25 \mu \mathrm{s} / 100 \mu \mathrm{s}$ (generated from (1) using parameters tabulated in Table 1)

\section{RESULTS AND DISCUSSION}

Plots of voltage drops for different strategies are shown with respect to different soil resistivity and the grounding arrangement points as previously illustrated in Fig. 3a, and Fig. 3b.

\section{A. Individual Ground-Side grounding (10 ohm-m soil resistivity)}

As shown in Fig. 5, Fig. 3a has been represented by a series of $\mathrm{R}, \mathrm{L}$ and $\mathrm{C}$ components and the resulting circuit has been modelled in PSpice software [4], [7], [8]. The voltage drops are determined at various locations (denoted from ' $\mathrm{A}$ ' to ' $R$ ') in the circuit as depicted in Fig. 5.

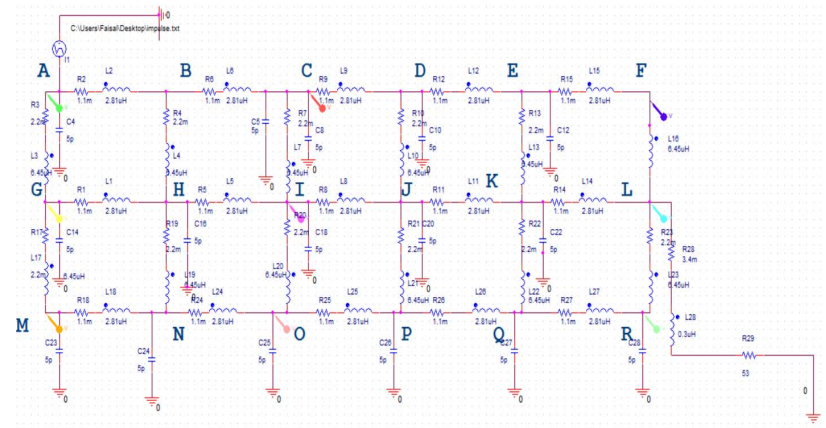

Fig. 5 PSpice simulation circuit model of individual grounding, side; Fig. 3a and various locations for voltage drop measurement (denoted from A to R)

However, for reason of clarity, only results for voltage drops at the point of injection (i.e. 'A'), in the midsection (i.e. ' $C$ ', 'G', 'M', 'I' and ' $\mathrm{O}$ '), near the ground point (i.e. 'F', and ' $R$ ') and the grounding point (i.e. 'L') are shown. Further, and for the same reason of clarity, the time display is up to $100 \mu \mathrm{s}$ as shown in Fig. 6. Fig. 7 is a zoomed in display of the voltage waveform up to $4 \mu \mathrm{s}$.

It can be seen that the highest (i.e. $2.5 \mathrm{MV}$ ) and lowest $(250 \mathrm{kV})$ voltage drops are at 'A' (i.e. lightning injection point and ' $\mathrm{L}$ ' (i.e. ground point) respectively. The locations of ' $\mathrm{C}$ ', ' $\mathrm{G}$ ', ' $\mathrm{M}$ ' ' $\mathrm{I}$ ' and ' $\mathrm{O}$ ' are in between $1 \mathrm{MV}$ and $2 \mathrm{MV}$. Locations of ' $F$ ' and ' $R$ ' have shown the voltage drops of between $500 \mathrm{kV}$ and $1 \mathrm{MV}$ which is the second lowest after the grounding point ' $\mathrm{L}$ '.

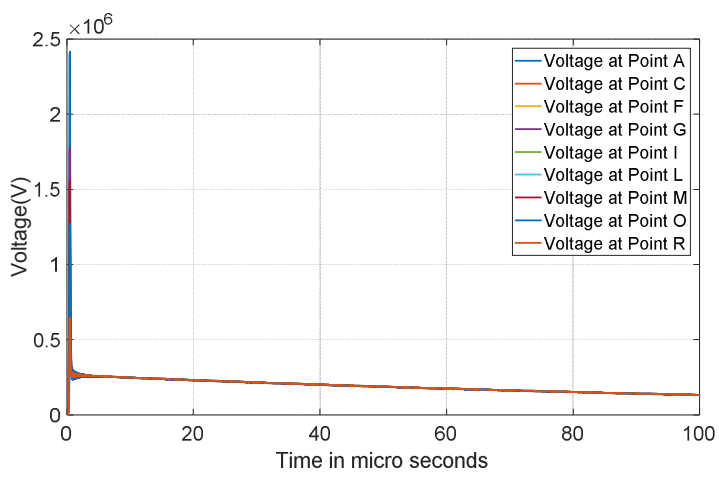

Fig. 6 Voltage drop measurements at various locations from A to R (10 ohm$\mathrm{m}$ soil resistivity for side grounding) 


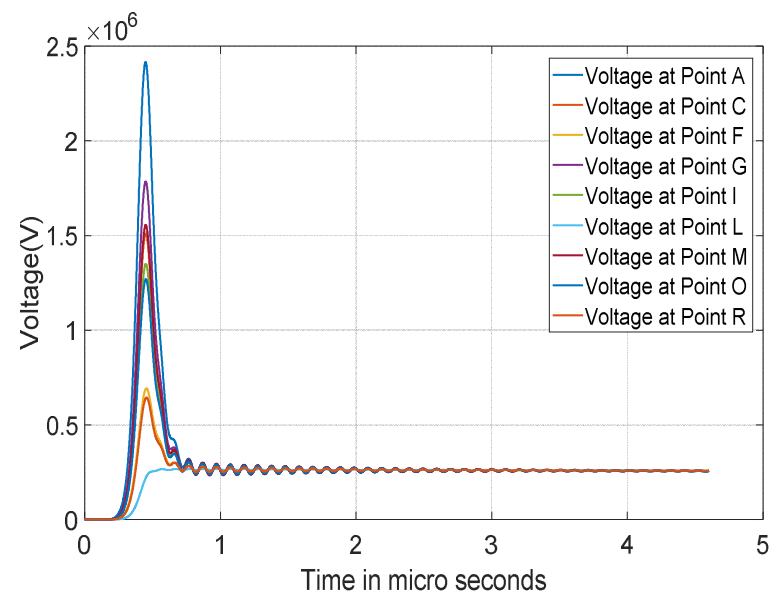

Fig. 7 Zoomed in version of Fig. 6

The scenarios considered were also modelled in COMSOL Multiphysics (RF Module) [9]. This is to allow the authors to check whether a PSpice approximation is acceptable. In COMSOL, the geometry (single assembly with side grounding) has been modelled in a $3 \mathrm{D}$ environment domain with dimensions of $20 \mathrm{~m}$ (depth) $\mathrm{x} 20 \mathrm{~m}$ (width) $\mathrm{x} 40 \mathrm{~m}$ (height) and meshed accordingly in normal size mesh. The ground domain was set to $10 \mathrm{ohm}-\mathrm{m}$ for soil resistivity with its boundaries set to be a perfectly matched layer (PML). PML ensures no reflections within the soil.

Furthermore, similar voltage drop evaluation points (denoted from ' $A$ ' to ' $R$ ') were used in COMSOL for an easy comparison with those denoted in PSpice and it is depicted in Fig. 8. The results using COMSOL are as plotted in Fig. 9 and its zoomed-in version is as plotted in Fig. 10. It is concluded that the results produced by both software packages are in agreement.

The simulation in COMSOL took a much longer time to complete despite using a six-core processor with $48 \mathrm{~GB}$ of RAM. This is probably due to the domain size and model configuration. Owing to the time consuming computation by COMSOL, the authors have continued the investigation using PSpice since the results obtained from both PSpice and COMSOL are equivalent.

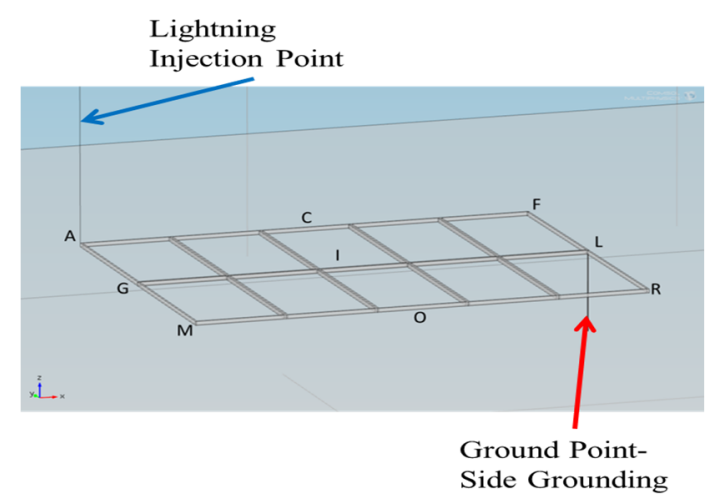

Fig. 8 COMSOL Multiphysics modelling environment

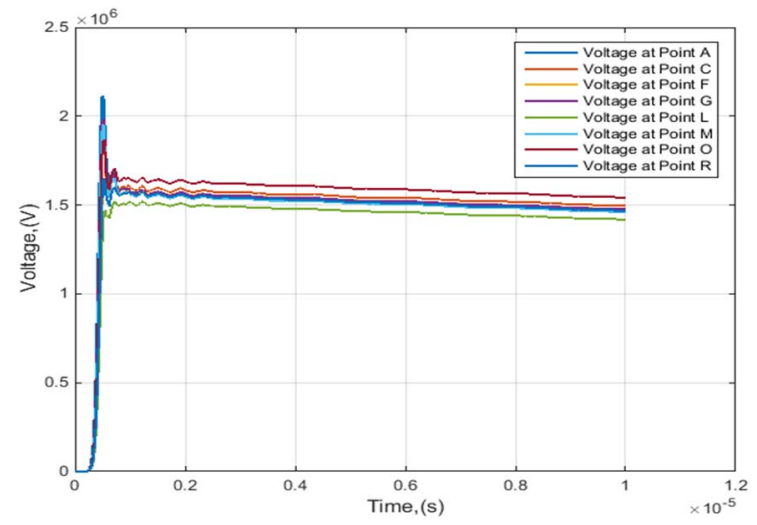

Fig. 9 Voltage drop calculations as obtained from COMSOL for $10 \mathrm{ohm}-\mathrm{m}$ soil resistivity and for side grounding

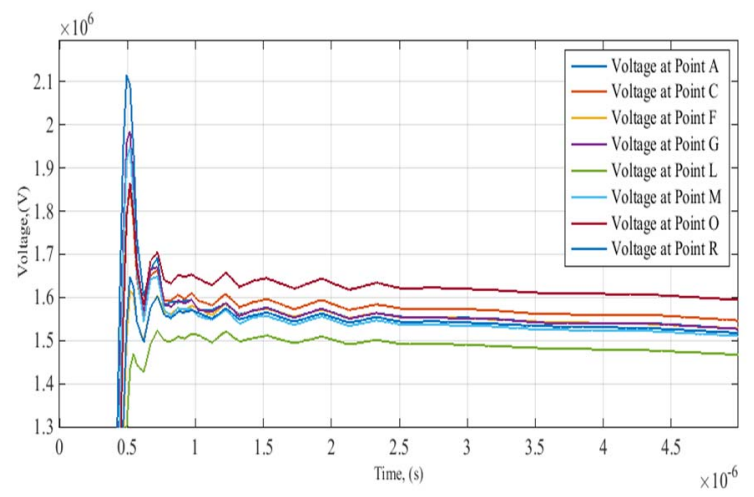

Fig. 10 Zoomed-in version of COMSOL results in Fig. 9

\section{B. Individual Ground - Side grounding (100 ohm-m soil resistivity)}

Similar circuit and setup as Fig. 5 were used but with soil resistivity configured to $100 \mathrm{ohm}-\mathrm{m}$. The voltage drop calculations at the same locations as denoted in Fig. 5 were used and the results obtained are as depicted in Fig. 11 and Fig. 12 is the zoomed-in version of it. It is found that the voltage drop at injection point ' $\mathrm{A}$ ' has increased to $3.5 \mathrm{MV}$ and the voltage drop at grounded point ' $\mathrm{L}$ ' has also increased to $2.5 \mathrm{MV}$ (from $250 \mathrm{kV}$ for $10 \mathrm{ohm}-\mathrm{m}$ of soil resistivity) when the soil resistivity of $100 \mathrm{ohm}-\mathrm{m}$ was applied. In contrast to the results with $10 \mathrm{ohm}-\mathrm{m}$ soil resistivity (see Fig. 7), the rest of the voltage drops evaluated are all relatively close together between $2.5 \mathrm{MV}$ and $3 \mathrm{MV}$.

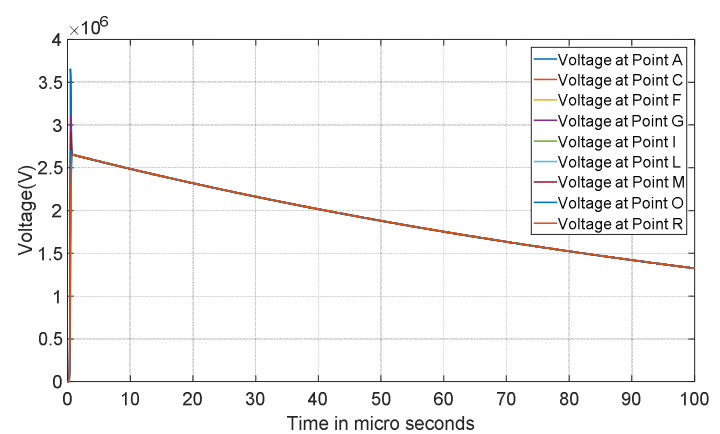

Fig. 11 Voltage drops evaluation at various locations from A to R (100 ohm-m soil resistivity for side grounding) 


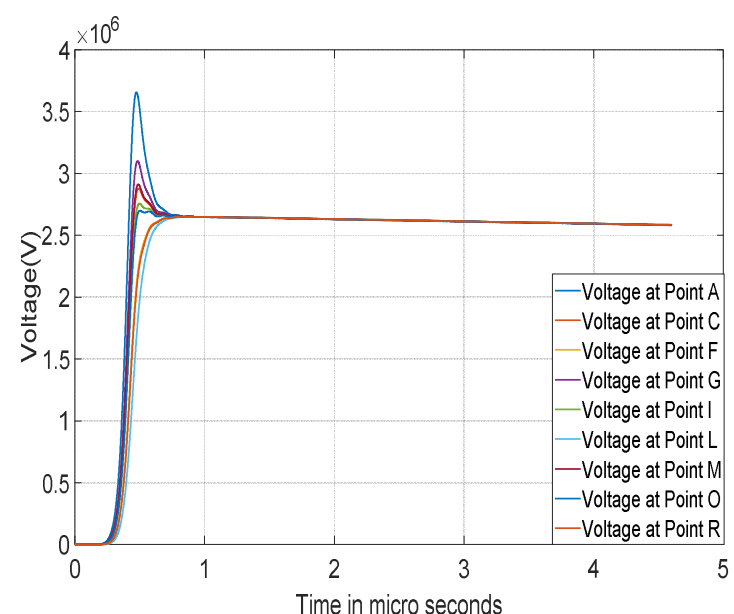

Fig. 12 Zoomed-in version of Fig. 11

\section{Individual Ground-Mid-section grounding (10 ohm-m soil resistivity)}

As shown in Fig. 13, Fig. $3 \mathrm{~b}$ has been similarly represented by using a series of $\mathrm{R}, \mathrm{L}$ and $\mathrm{C}$ components. However, the grounding point has been changed to point ' $I$ '. As in the case for side-grounding, voltage drops evaluation (at various locations denoted from ' $A$ ' to ' $R$ ') was used and as depicted in Fig. 13.

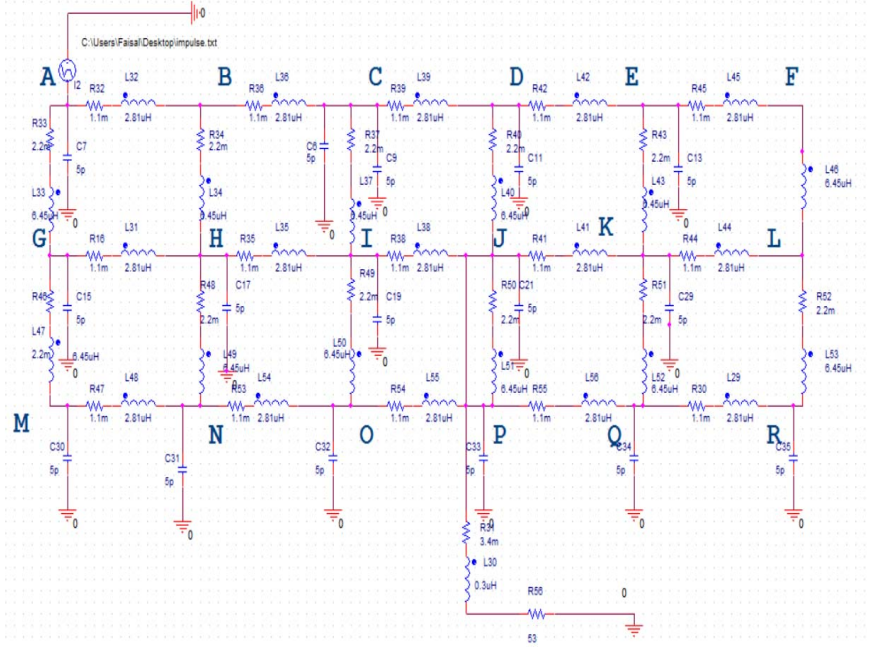

Fig. 13 PSpice simulation circuit model of mid-section grounding; Fig. 3b and the various locations for voltage drops evaluation (denoted from A to $\mathrm{R}$ )

Results for voltage drops at point of injection (i.e. 'A'), surrounding the ground points (i.e. ' $F$ ', ' $G$ ', 'L', ' $M$ ' and ' $R$ '), near the ground points (i.e. ' $\mathrm{C}$ ', and ' $\mathrm{O}$ ') and grounding point (i.e. 'I') are displayed in Fig. 14 up to $100 \mu$ s. Fig. 15Fig. 7 is the zoomed-in display of selected voltage drops up to $5 \mu \mathrm{s}$.

The voltage drop at the injection point was found to be the highest (1.7MV) and it is $30 \%$ less when compared to the side grounding (see Fig. 7). The lowest voltage drop was seen (i.e. around $250 \mathrm{kV}$ ) at point $\mathrm{C}$ and the second lowest was measured at point ' $\mathrm{L}$ ' (i.e. around $300 \mathrm{kV}$ ). However, the point (i.e. point 'I') connected to down conductor was measured at $400 \mathrm{kV}$. Furthermore, the rest of the calculated voltage drops were between $500 \mathrm{kV}$ and $1 \mathrm{MV}$.

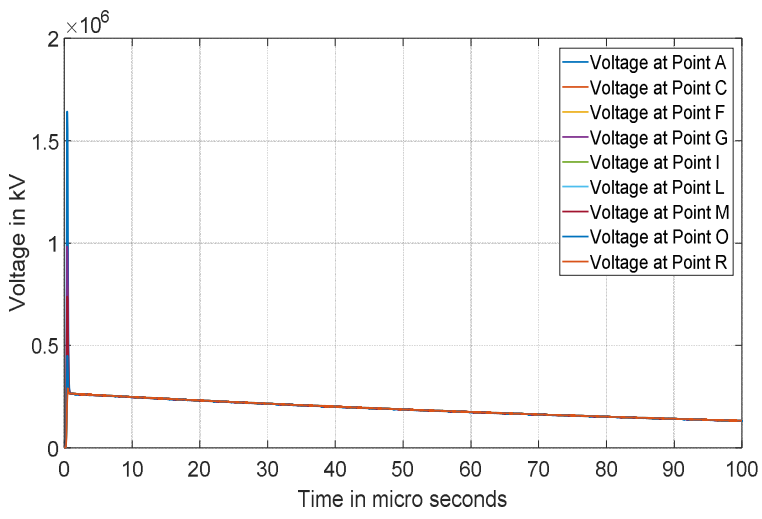

Fig. 14 Voltage drop measurements at various locations from A to R (10 ohm$\mathrm{m}$ soil resistivity for mid-section grounding)

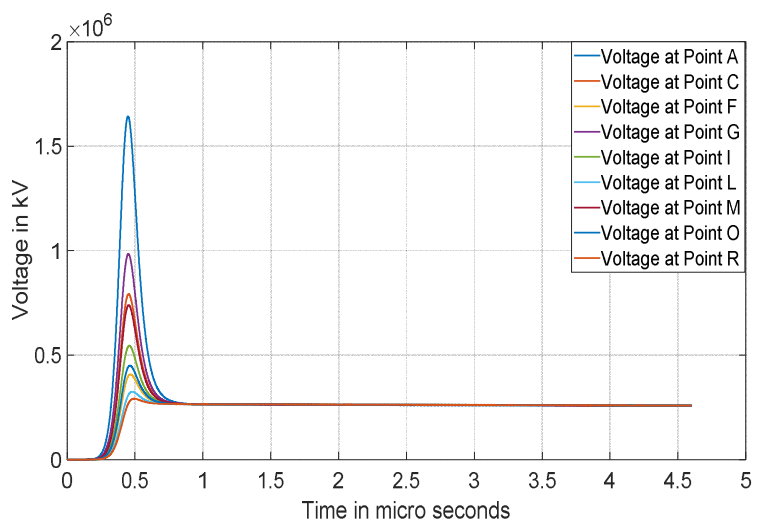

Fig. 15 Zoomed-in version of Fig. 14

\section{Individual Ground-Mid-section grounding (100 ohm-m soil resistivity)}

Similar circuit and setup as Fig. 13 were used but with a soil resistivity of $100 \mathrm{ohm}-\mathrm{m}$. The voltage drops were evaluated at the same locations as denoted in Fig. 13 and the results obtained are as depicted in Fig. 16.

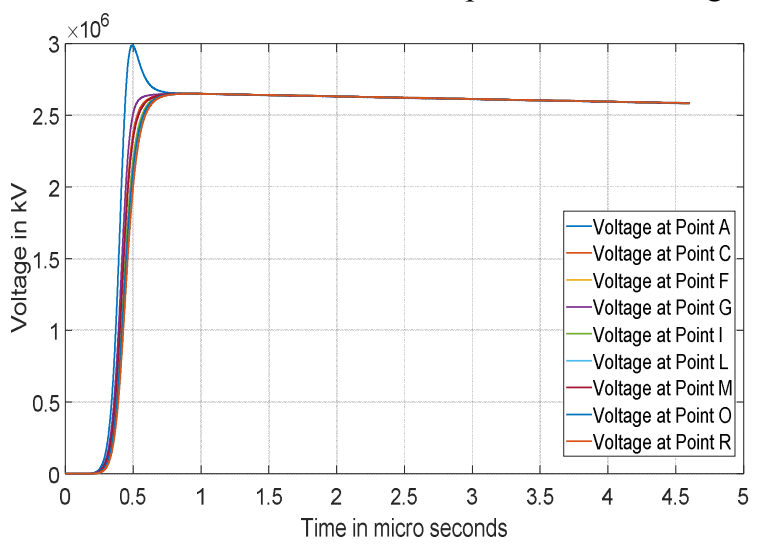

is the zoomed-in version up to $5 \mu \mathrm{s}$. It is noted that the voltage drop evaluated at the point of injection (i.e. point A) has increased to $3 \mathrm{MV}$ which is double the value when compared to that with $10 \mathrm{ohm}-\mathrm{m}$ soil resistivity. However, the voltage drop evaluations for the rest of the points are found to be within the same range of just over $2.5 \mathrm{MV}$. 


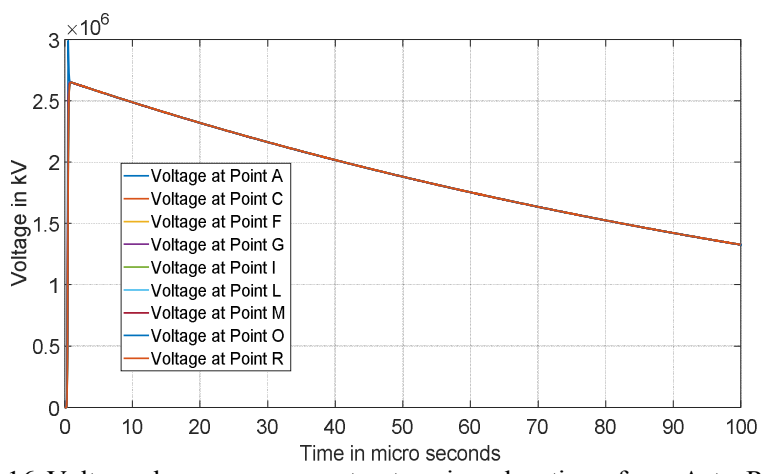

Fig. 16 Voltage drop measurements at various locations from A to R (100 ohm-m soil resistivity for mid-section grounding)

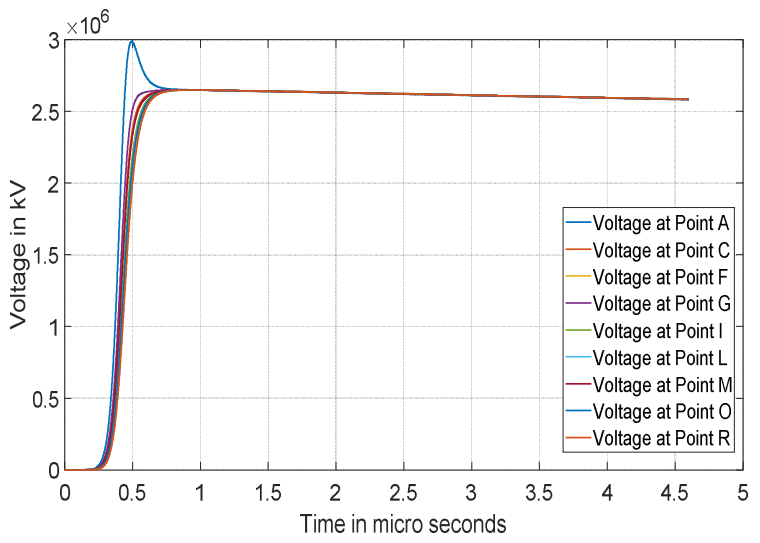

Fig. 17 Zoomed-in version of Fig. 16

\section{CONCLUSIONS}

A study of grounding strategies for solar PV panels has been presented by considering 2 different positions of the PV assembly for grounding and also for 2 different soil resistivity of $10 \mathrm{ohm}-\mathrm{m}$ and $100 \mathrm{ohm}-\mathrm{m}$.

Results obtained using PSpice have shown to be reasonably accurate because they were equivalent to that generated by COMSOL.

The results for side grounding with different soil resistivities were compared and it is found that voltage drops at the grounded point of an assembly varied significantly. On the other hand, the results obtained for mid-section grounding arrangement with different soil resistivities have apparently shown that mid-section grounding may not be advisable because it does not offer any obvious advantage.

Therefore, for a single assembly, side grounding may be the best grounding strategy to be adopted. Further work will be conducted on different points of lightning attachment for a single solar PV assembly, and for groups of solar PV assembly.

\section{REFERENCES}

[1] W. I. Bower and J. C. Wiles, "Analysis of Grounded and Ungrounded Photovoltaic Systems," in Proceedings of 1994 IEEE 1st World Conference on Photovoltaic Energy Conversion - WCPEC (A Joint Conference of PVSC, PVSEC and PSEC), 1994, vol. 1, pp. 809-812.

[2] BS EN 62305-1:2011 Protection against lightning Part 1: General principles. 2011.

[3] J. C. Wiles, "Photovoltaic System Grounding Prepared by: Solar America Board for Codes and Standards," no. October. Solar America Board for Codes and Standards, 2012.

[4] C. A. Charalambous, N. D. Kokkinos, and N. Christofides, "External lightning protection and grounding in large-scale photovoltaic applications," IEEE Trans. Electromagn. Compat., vol. 56, no. 2, pp. 427-434, 2014.

[5] Z. Benesova, R. Haller, J. Birkl, and P. Zahlmann, "Overvoltages in Photovoltaic Systems Induced by Lightning Strikes," in 2012 31st International Conference on Lightning Protection, ICLP 2012, 2012.

[6] SMA Solar Technology AG, "Technical Information-Capacitive Leakage Currents," vol. 2.5, p. 11, 2015.

[7] OrCAD, "PSPICE-Personal Computer Simulation Program with Integrated Circuit Emphasis." [Online]. Available: http://www.orcad.com/products/orcad-pspice-designer/overview. [Accessed: 25-Feb-2018].

[8] J. Birkl and P. Zahlmann, "Specific Requirements on SPDs Installed on the DC-side of PV-Generators," in 2010 30th International Conference on Lightning Protection, ICLP 2010, vol. 2010, pp. 1-13.

[9] C. M. Ltd, “COMSOL Multiphysics - User's Guide, Ver. 4.3a.”. 